\title{
Teatro com adolescentes em risco social: práticas de promoção da saúde no contexto terapêutico ocupacional
}

\author{
Theater with adolescents at social risk: health \\ promotion practices in an occupational \\ therapy context
}

\author{
Francisca Milena Cruz Justa1, Isabel Cristina Luck C. de Holanda²
}

JUSTA, F. M. C.; HOLANDA, I. C. L. C. Teatro com adolescentes em risco social: práticas de promoção da saúde no contexto terapêutico ocupacional. Rev. Ter. Ocup. Univ. São Paulo, v. 23, n. 1, p. 16-23, jan./abr. 2012.

\begin{abstract}
RESUMO: O estudo teve como objetivo analisar a utilização da linguagem artística do teatro para a promoção da saúde de adolescentes em risco social no contexto terapêutico ocupacional, mediante a experiência obtida no grupo GESTTO (Grupo de Expressões Sócio-Teatrais em Terapia Ocupacional), composto por adolescentes moradores de uma comunidade, na cidade de Fortaleza-CE. Utilizou-se da abordagem qualitativa e da pesquisa-ação como método de investigação baseandose nos escritos de Liberman, Barros, Boal e Moreno. Os resultados da análise destacaram que o grupo terapêutico ocupacional reverberou no adolescente a percepção de si mesmo como um ser em sociedade, detentor de um papel, com potencial para criar e ser um agente transformador. Problematiza-se, portanto, a funcionalidade do teatro como um recurso terapêutico ocupacional.
\end{abstract}

DESCRITORES: Adolescente; Vulnerabilidade; Cultura; Arte; Terapia ocupacional; Promoção da saúde.

\footnotetext{
1. Graduada em Terapia Ocupacional pela Universidade de Fortaleza - UNIFOR.

2. Graduada em Terapia Ocupacional pela Universidade de Fortaleza - UNIFOR, mestre em Educação em Saúde pela UNIFOR, docente do curso de Terapia Ocupacional da Universidade de Fortaleza - UNIFOR.

Endereço para correspondência: Francisca Milena Cruz Justa - Alameda das Cecílias, nº 169, quadra 33, Cidade 2000. CEP: 60190280. E-mail: milena_justa@hotmail.com
} 


\section{INTRODUÇÃO}

$\mathrm{O}$ presente estudo é fruto das vivências e identificações da pesquisadora com o teatro, enquanto linguagem e produção artísticocultural, que motivaram a criação do Grupo de Expressões Sócio-Teatrais em Terapia Ocupacional (GESTTO), um projeto acadêmico de extensão, que assistiu, durante os semestres de 2008.2 e 2009.1, adolescentes em risco social, moradores de uma comunidade localizada na cidade de Fortaleza-CE. O grupo utilizou a linguagem teatral no âmbito da terapia ocupacional objetivando a promoção da saúde destes adolescentes.

Além da inclinação pessoal da autora, a escolha do tema se deu no intuito de complementar o quadro de pesquisas referentes ao adolescente em risco social e à presença de linguagens artísticas, em especial a do teatro, nas práticas de promoção da saúde, particularmente no contexto terapêutico ocupacional.

O termo risco é usado como um fator de ordem física, social ou comportamental que submete o sujeito a um resultado negativo ou indesejado em sua vida (ANTONI; KOLLER, 2000; SAITO, 2001).

Os adolescentes referidos encontravam-se numa situação de risco relativa ao seu contexto sócio-habitacional, onde eram afetados por problemas com drogas, alcoolismo, violência, criminalidade, gravidez precoce, ociosidade, bem como a falta de condições dignas de educação e moradia, fazendo parte de uma grande parcela da população brasileira, que, massificada pela detenção do poder, alienada pelos meios de comunicação e segregada pelo funcionamento das classes sociais, acaba perdendo o contato com sua essência criativa e questionadora, com sua singularidade e, por conseguinte, com sua força de transformação social.

Diante do exposto, buscou-se, a partir do estudo da experiência do GESTTO, analisar o teatro enquanto ferramenta de promoção da saúde. Para tanto foram levantados os benefícios que o teatro trouxe para um grupo de adolescentes em risco social em um contexto terapêutico ocupacional e problematizados os seguintes temas: o teatro como elemento facilitador na construção da subjetividade; o teatro como promotor da percepção da potência de transformação social e participação sócio-cultural; o teatro enquanto linguagem e produção artístico-cultural como recurso utilizado em terapia ocupacional.

Portanto, o estudo teve como objetivo analisar a utilização da linguagem artística do teatro para a promoção da saúde de adolescentes em risco social no contexto terapêutico ocupacional.

\section{O cenário das transformações}

Durante a adolescência todo indivíduo passa por significativas mudanças na forma como percebe a si mesmo e ao seu corpo. Aberastury e Knobel (1981) descrevem este período como sendo de desequilíbrios e de instabilidades extremos, necessários para o estabelecimento do objetivo fundamental desta etapa, que é a construção da identidade. Desta forma, pode-se dizer que a marca da adolescência é a busca por si próprio.

A reorganização psíquica ocorre em todas as fases do desenvolvimento humano, mas de uma forma muito significativa na adolescência. De acordo com Levisky (2000) há a reativação do conflito edípico, onde o sujeito tem a oportunidade de resgatar e corrigir possíveis falhas no seu desenvolvimento, amenizando algumas de suas fixações. Deste modo, o processo de reelaboração que ocorre, necessita de amparo e referências no âmbito familiar e social.

Porém, contemporaneamente, muitos são os percalços encontrados pelos adolescentes no processo de subjetivação. Segundo Abeche et al. (2005), no seio familiar, é comum a constatação da instabilidade das relações e a dissolução de referências e valores essenciais à organização do sujeito; e já na sociedade, a massificação e o excesso de informações vêm destruindo a capacidade de discernimento dos indivíduos, levando-os a caminhar da individualidade para o individualismo, em outras palavras, do ser sujeito para o ser consumidor.

Para Hermans (apud Oliveira, 2006), de acordo com o contexto social, o adolescente é levado à adesão de novos papéis na família, na escola, e em seus grupos, tendo que responder cada vez mais às novas solicitações da realidade em que vive. Sobre isso, Silva e Avelino (2004) concluíram que o adolescente em risco social constrói uma pseudomaturidade a serviço da exigência social que sofre, já que é imperiosa a necessidade de assumir responsabilidades de adulto, como cuidar de casa, trabalhar e custear as próprias despesas. Assim, não há tempo para experimentar e viver a adolescência e nem elementos suficientes que permitam a simbolização

Neste sentido, há a necessidade da criação de novos espaços na clínica com adolescentes. Rozenthal (2006, p.124) ressalta que podemos de maneira esquemática dizer que “aquilo que está em jogo, na clínica do jovem no início deste século não é mais, prioritariamente, dar um novo sentido aos sintomas [...] é a criação da subjetividade, isto é, franquear a possibilidade da construção de si”.

Em relação à clínica com adolescentes, é preciso considerar também que a sociedade contemporânea tende 
a obstruir processos capazes de ensejar a diferença e a singularização, e de resistir, construindo outros modos de sensibilidade, indo ao encontro do desejo, do gosto de viver e da vontade de construir o mundo em que habita (LIBERMAN, 1988). Para a mesma autora (2002), tais processos de subjetivação podem ser facilitados pelo trabalho com o corpo e a (re) criação de suas formas de expressão.

A Terapia Ocupacional social atua com base no que emerge das contradições desta sociedade, marcada pela desigualdade e pela presença crescente de grandes contingentes da população submetidos à marginalização, dissolução de vínculos e vulnerabilização das redes sociais, como sugerem Barros et al. (2007). Portanto, a prática com adolescentes em situação de risco social deve fortalecer as potencialidades de transformação dessa situação e para tal há a necessidade de experimentação e singularização desse ser, de validação do seu potencial expressivo, e de apropriação da sua capacidade transformadora.

Segundo Dall'Orto (2008) o Teatro do Oprimido, método teatral criada por Augusto Boal, tem como finalidade provocar a desmecanização física e intelectual dos corpos de seus praticantes, ou seja, propõe que rompam com a máscara criada pela sujeição nos ângulos social e subjetivo. Boal (1990, 2009), ressalta que o teatro faz com que cada um se aproprie da potência transformadora que originalmente é sua. O mesmo autor enfatiza que, o teatro foi a primeira invenção humana, e a partir da qual o homem pôde ver-se agindo, perceber-se na sua própria ação, ser espectador de si próprio, analisar a situação em que se encontra e, como um diretor, se auto-dirigir durante sua própria atividade.

Nesta perspectiva, exercendo o teatro, o adolescente poderia tornar-se mais capaz de se avaliar durante sua ação frente à sociedade, assim como de modificar seus comportamentos e atitudes e o próprio meio em que vive.

Para o criador do Teatro Espontâneo, Moreno (1975), o objetivo da linguagem teatral é favorecer espaço para um ato criador que dê vazão à espontaneidade e criatividade dos atores sociais. Por espontaneidade entende-se a capacidade que opera no aqui e agora, propelindo o indivíduo a dar uma resposta adequada a uma nova situação ou uma resposta nova e também adequada para uma situação já conhecida.

Portanto, vislumbra-se que, mediante a experimentação corporal cênica no âmbito da terapia ocupacional, o sujeito perceba-se em sua potência de transformação, criatividade, e capacidade de transcender os limites que se impõe sobre ele. Esta proposta inserese no conjunto de ações que proporcionam aos sujeitos tornarem-se mais ativos na promoção e prevenção de sua própria saúde. A promoção da saúde é entendida como um dos eixos da atenção primária, a qual se utiliza de um conceito ampliado de saúde, visando promover qualidade de vida, equidade e redução de riscos, ampliando também, a autonomia e a co-responsabilidade dos sujeitos no cuidado a sua saúde (BRASIL, 2007).

\section{PROCEDIMENTOS METODOLÓGICOS}

A presente pesquisa foi realizada mediante abordagem qualitativa, na qual segundo Chizzoti (2006), obtém-se um conhecimento mais profundo do caso, onde estão envolvidas forças não-mensuráveis pertencentes ao mundo subjetivo e ao contexto social dos sujeitos. Utilizou-se a pesquisa-ação descrita por Thiollent (apud LEOPARDI, 2001) como método que permite a ação conjunta do pesquisador e pesquisado, que presenciam juntos as mudanças ocorridas.

Para Thiollent (1994), a pesquisa-ação pretende fornecer aos sujeitos estudados, maior capacidade de transformação do problema. Deste modo, o pesquisador, durante o estudo ajudou ao grupo a problematizar o que foi constatado como problema, ou seja, possibilitou a ampliação da consciência dos envolvidos, a fim de que os mesmos planejassem as formas de transformação de suas ações.

O estudo se deu nas dependências do serviço de Terapia Ocupacional do Núcleo de Atenção Médica Integrada (NAMI), Unidade de Saúde subsidiada pela Universidade de Fortaleza (UNIFOR), na cidade de Fortaleza, Ceará, tendo a duração de três meses (março a maio de 2009), com periodicidade de duas vezes por semana, sob o tempo aproximado de uma hora e meia para cada reunião com o grupo. Os participantes foram 09 adolescentes do grupo GESTTO, de faixa etária entre 14 a 18 anos, regularmente matriculados na escola e moradores da Comunidade do Dendê.

Como técnica de coleta de dados utilizou-se a observação participante (CHIZZOTTI, 2006), obtida por meio do contato direto do pesquisador com o assunto observado; o diário de campo (MINAYO, 1994) que foi um instrumento em que o pesquisador registrou as suas observações e impressões sobre o assunto; e o grupo focal (LEOPARDI, 2001), no qual os dados coletados foram diretamente extraídos das falas do grupo, que relataram suas experiências e percepções.

Os resultados foram analisados pelo método de análise de conteúdo que seguiu os três pólos cronológicos (pré-análise, exploração do material e tratamento dos resultados, e interpretação) visando à descrição do conteúdo das informações obtidas (BARDIN, 1977).

A pesquisa foi realizada de acordo com os princípios 
éticos da Resolução 196/96, que incorpora os referenciais básicos da bioética: autonomia, não maleficência, beneficência e justiça, entre outros, com o parecer de número 407/08 do Comitê de Ética em Pesquisa da Universidade de Fortaleza.

Para formalizar a adesão dos pesquisados, foi utilizado o Termo de Consentimento Livre Esclarecido, por meio do qual seus pais ou responsáveis receberam todas as informações a respeito da pesquisa e assinaram consentindo ou não a participação do filho (a). Já para formalizar a permissão da instituição, foi aplicado o termo de Consentimento Institucional, no qual constavam todos os elementos relevantes da pesquisa, sendo também solicitada a assinatura do responsável pela instituição.

\section{RESULTADOS E DISCUSSÃO}

Durante o processo terapêutico, ao decorrer de cada encontro, as intervenções foram realizadas em ambiente acolhedor, de forma descontraída, por meio de práticas de sensibilização, expressão corporal e de dinâmicas de integração grupal; experimentações espontâneas foram seguidas de discussões sobre os temas sociais abordados e criação coletiva de conhecimentos. Assim como para Moreno (1975), a espontaneidade e a criatividade do ator eram a principal preocupação, bem como a sinceridade e a integridade, que significavam muito mais do que sua maestria.

Para melhor compreensão dos resultados da pesquisa se fez necessária a caracterização da população do estudo, que está descrita na Tabela 1 , onde se encontram nome, idade, escolaridade e motivo pelo qual os adolescentes entraram no grupo. A fim de preservar o seu anonimato, foi utilizado para identificá-los o termo participante e números, atribuídos aleatoriamente.

Tabela 1. Caracterização dos adolescentes e de suas intenções ao buscar o teatro

\begin{tabular}{|c|c|c|c|}
\hline Nome fictício & Idade & Escolaridade e outras atividades & Intenção ao entrar no teatro \\
\hline Participante 1 & 14 anos & $\begin{array}{l}\text { "Faço o } 9^{\circ} \text { ano e cuido dos meus irmãos } \\
\text { mais novos" }\end{array}$ & $\begin{array}{l}\text { "Conhecer mais o teatro e estudar para ter uma } \\
\text { oportunidade" }\end{array}$ \\
\hline Participante 2 & 16 anos & $\begin{array}{l}\text { "Faço a 9a série, e trabalho desenhando } \\
\text { roupas numa loja” }\end{array}$ & $\begin{array}{l}\text { "Entrei porque eu amo teatro e gostaria de fazer } \\
\text { sucesso" }\end{array}$ \\
\hline Participante 3 & 18 anos & $\begin{array}{l}\text { "Curso o } 3^{\circ} \text { ano, sou professora de reforço } \\
\text { e de catecismo, e participo da igreja” }\end{array}$ & $\begin{array}{l}\text { "Gosto de teatro e quero conhecer melhor minhas } \\
\text { capacidades”. }\end{array}$ \\
\hline Participante 4 & 15 anos & $\begin{array}{l}\text { "Faço o } 9^{\circ} \text { ano, brinco, estudo e vou pra } \\
\text { igreja" }\end{array}$ & $\begin{array}{l}\text { "Eu queria participar de algum grupo e aprender } \\
\text { alguma coisa" }\end{array}$ \\
\hline Participante 5 & 14 anos & “Estudo, faço o $9^{\circ}$ ano e cuido da casa” & $\begin{array}{l}\text { "Vieram na minha sala de aula falar do GESTTO } \\
\text { e eu me interessei" }\end{array}$ \\
\hline Participante 6 & 15 anos & $\begin{array}{l}\text { "Vou pra escola }\left(9^{\circ} \text { ano) e depois vou cuidar }\right. \\
\text { dos meus } 2 \text { irmãos, fazer comida e esperar } \\
\text { minha mãe chegar do trabalho”. }\end{array}$ & $\begin{array}{l}\text { "Foi pra poder conhecer mais esse trabalho e po- } \\
\text { der aprender mais e desenvolver mais as minhas } \\
\text { criatividades perdidas". }\end{array}$ \\
\hline Participante 7 & 15 anos & $\begin{array}{l}\text { "Eu faço o } 9^{\circ} \text { ano, atletismo e freqüento os } \\
\text { grupos da igreja". }\end{array}$ & $\begin{array}{l}\text { "Entrei porque sabia que ia aprender bastante } \\
\text { coisas novas" }\end{array}$ \\
\hline Participante 8 & 17 anos & $\begin{array}{l}\text { "Faço o } 1^{\circ} \text { ano na escola, cuido de casa e } \\
\text { participo de atividades na igreja” }\end{array}$ & "Eu vim porque uma amiga me chamou" \\
\hline Participante 9 & 18 anos & $\begin{array}{l}\text { "Estudo de manhã no } 3^{\circ} \text { ano e trabalho de } \\
\text { tarde e de noite como vigia" }\end{array}$ & "Foi minha namorada quem me chamou” \\
\hline
\end{tabular}

FONTE: JUSTA, F. M. Instrumento de coleta de dados da pesquisa intitulada Teatro com adolescentes em risco social: práticas de promoção da saúde no contexto terapêutico ocupacional: diário de campo. Fortaleza, 2009.

Após a aplicação da observação participante e do grupo focal ao final da pesquisa, evidenciaram-se discursos bastante significativos, agrupados nas seguintes categorias:
1.A experiência de fazer parte do GESTTO;

2.Contribuições e mudanças;

3.A percepção de si e do seu papel frente à sociedade; 
4.Transformações concretas;

5.A função terapêutica do teatro e sua utilização em terapia ocupacional.

\section{1- A experiência de fazer parte do GESTTO}

Indagados sobre a experiência de participar do grupo, a maioria dos adolescentes relatou questões que vão além do fazer teatro, como sentimentos de prazer, alegria e acolhimento.

“... Fazer parte do GESTTO é algo que me faz muito feliz” (Participante 3; JUSTA, 2009).

“... nunca tinha participado de um grupo tão alegre e descontraído.” (Participante 2; JUSTA, 2009).

Para Espinosa, a alegria é o que se sente quando se percebe o aumento da realidade, isto é, da força interna e da capacidade para agir, do pensamento e da ação, sendo o caminho para a autonomia individual e política (CHAUÍ apud LIBERMAN, 1998).

No setting terapêutico do grupo funcionava o que era chamado de "regra do absurdo", onde todos podiam ser e fazer o que quisessem desde que não atrapalhassem a condução das atividades e a expressividade dos colegas. Desse modo, muitos adolescentes encaravam o GESTTO como um espaço onde era permitido brincar, sonhar, chorar, sorrir, se expor, ser ridículo ou sério, forte ou fraco, belo ou feio, bom ou perverso.

"No teatro nós se inspira no personagem e fala o que pensa” (Participante 9; JUSTA, 2009)

"Quando encarnamos um personagem ele pode ter os mesmos problemas que a gente, naquele personagem podemos colocar pra fora o que nos aflige (Participante 6; JUSTA, 2009).

Nota-se que através da prática teatral há uma identificação do ator com o personagem, onde pode ocorrer a mobilização de afetos e emoções capaz de dar novo significado aos seus conteúdos no ato da ação, que Moreno (1975) denomina de catarse de integração. Segundo este teórico, no teatro há a possibilidade de recapitular problemas não resolvidos num contexto social mais livre, mais amplo e mais flexível.

\section{2- Contribuições e mudanças}

Ao ser indagada sobre a contribuição que o teatro trouxe para suas vidas, e sobre possíveis mudanças depois da entrada no grupo, a maioria dos adolescentes relatou benefícios e transformações na sua relação com os outros, consigo mesmo e com o mundo.

“(...) eu sou muito tímido, mas agora já tô falando mais”. (Participante 4; JUSTA, 2009).

"Comecei a ver o mundo totalmente diferente, a ter vontade de ajudar os outros que precisam, porque nós estamos bem, mas tem outros muito mal..." (Participante 5; JUSTA, 2009).

“(...) antes eu tentava me esconder do problema, agora não (...) corro atrás de soluções tentando superar os obstáculos (...) mudei muito e continuo mudando, antes não tava nem aí pro mundo, pras pessoas, até na minha casa eu tratava meus irmão e minha mãe com indiferença (...) agora não, aprendi que a gente deve respeitar pra ser respeitada e ajudar ao próximo com amor e solidariedade". (Participante 6; JUSTA, 2009).

Neste sentido, pode-se falar que a prática teatral no contexto terapêutico provocou mudanças no posicionamento dos adolescentes frente a si mesmos e à sociedade, pois estes passaram a se colocar como indivíduos mais participativos e conscientes de sua coletividade, e com maior vontade e atitude para enfrentar a vida. Liberman (2002) afirma que diferentes vivências no campo das artes podem contribuir para que o sujeito se perceba como tal, identifique seus diferentes modos de funcionamento, para em seguida repensá-los e reconstruí-los, ou seja, a arte dá ao viver uma experiência criativa de si mesmo. Almeida (2004) corrobora enfatizando que o fazer com o corpo é constituidor de novas subjetividades, ou seja, de novas formas de estar no mundo.

\section{3- A percepção de si e do seu papel frente à sociedade}

Questionados sobre como se percebiam e como enxergavam seu papel frente à coletividade, notou-se o quanto os adolescentes começaram a refletir sobre a sociedade em que viviam e sua função nela.

"Agora eu sei que não sou diferente de ninguém, todos somos seres humanos, não importa se é rico ou pobre, negro ou branco, o que importa é a gente ser feliz e se aceitar (...) me acho tão pequena no meio de tanta ignorância (...) gente matando, roubando (...) às vezes me 
pergunto por que (...) e me percebo só, como se eu fosse apenas eu e não tivesse nenhum significado em existir". (Participante 6; JUSTA, 2009).

"Acho que devo ajudar a cada um que necessita da minha ajuda (...) não posso me distanciar daqueles que precisam de mim (...) da minha sociedade. (Participante 5; JUSTA, 2009).

"Me percebo como uma pessoa que pode transformar sua realidade (...) posso mudar minha vida e também de outras pessoas que necessitam de ajuda". (Participante 1; JUSTA, 2009).

É importante ressaltar que os adolescentes parecem ter se percebido mais responsáveis pela sua realidade, assim como mais capazes de transformá-la. Eles relatam que têm o papel de modificar o meio em que vivem para ajudar aqueles que precisam de ajuda, se colocando sempre no lugar do outro e entendendo a sua função ativa dentro da sociedade. Moreno (1975) vê cada ser humano como co-responsável por todos os outros, pelo seu meio ambiente e pelo cosmos, como capaz de se colocar no lugar do outro, de viver com o outro um encontro existencial.

\section{4- Transformações concretas}

Ao ser consultada se havia conseguido mudar alguma coisa em sua realidade social, a maioria relatou que conseguiu resolver algumas questões em seu cotidiano familiar, escolar, ou outros, que melhoraram sua qualidade de vida.

“Consegui mudar o jeito de pensar da minha família”. (Participante 1; JUSTA, 2009).

"Melhorou muito meu convívio com meus familiares". (Participante 3; JUSTA, 2009).

"Parei de ter vergonha dos outro, na escola, na família, dos colegas (...) quando era pra apresentar trabalho eu só ficava lá atrás e hoje quase não paro de falar”. (Participante 7; JUSTA, 2009).

Dois adolescentes (Participante 3 e "Participante 2”), que estão no GESTTO desde o seu início, há dois semestres, comprometeram-se a dar continuidade ao grupo após o término do projeto. Segundo os mesmos, a direção da escola na qual estudam estaria esperando uma verba do governo que seria aplicada na contratação de oficineiros da comunidade para lecionar atividades extra- curriculares. Como já conhecia o grupo, a escola optou pelo teatro, aceitando contratar a "Participante 3" para tal. O "Participante 2" se ofereceu para formar uma dupla com a mesma.

Desta forma, estes adolescentes tiveram a possibilidade de transformar a realidade em que viviam e de se tornar multiplicadores do que aprenderam, fazendo do teatro uma ferramenta de diálogo com a sua comunidade. A Declaração de Princípios da Associação Internacional do Teatro do Oprimido (AITO) refere que a raiz da relação Opressores-Oprimidos está no fato de que os diálogos humanos tendem a virar monólogos, onde os oprimidos são aqueles indivíduos ou grupos despossuídos social, cultural, política, econômica, racial ou sexualmente do seu direito ao diálogo. Portanto, a linguagem teatral se propõe a dar voz a estas camadas oprimidas e a restaurar o diálogo.

Na Terapia Ocupacional busca-se como propósito a emancipação e autonomia do sujeito (COVAS, 2003). Os jovens agiram como sujeitos transformadores, onde ao mesmo tempo em que modificavam a matéria de sua expressão (corpo, gesto, sentimentos, etc.) também se modificavam, e a percepção dessa potência de transformação tornava-os mais capazes de mudar os elementos do seu meio social, fornecendo-lhes maior empoderamento sobre suas vidas.

\section{5- A função terapêutica do teatro e sua utilização em terapia ocupacional}

Ao serem indagados sobre como percebiam o teatro sendo utilizado de forma terapêutica, apareceram as seguintes respostas:

"O teatro é um recurso que pode mudar a vida de muito adolescente da nossa comunidade..." (Participante 4; JUSTA, 2009).

“... o teatro é maravilhoso porque a gente se transforma e pode ver que o mundo também precisa de transformação”. (Participante 6; JUSTA, 2009).

"Eu acho muito legal porque o teatro não só ensina a ser ator ou atriz, mas sim a pensar e agir de outra forma”. (Participante 1; JUSTA, 2009).

As falas dos adolescentes retratam alguns dos extravasamentos da linguagem teatral no contexto terapêutico. Eles perceberam que o fazer teatral vai além da encenação, e tem a capacidade de promover transformações, tanto individuais quanto coletivas.

Sabe-se que o recurso terapêutico ocupacional é a 
atividade humana desdobrada em conteúdo significativo, ou seja, o meio usado para facilitar ou mediar a transformação do sujeito (PEDRAL; BASTOS, 2008). Para as autoras, as formas expressivas e criativas representam um caminho mais rico em conteúdo, e por sua complexidade, facilitam a manifestação da realidade do sujeito, de sua essência.

Desta forma, o teatro, enquanto linguagem artística e produção de cultura, explorado no contexto terapêutico ocupacional, pode passar a ser visto também em suas potencialidades terapêuticas, direcionando-se para uma nova compreensão, a de recurso terapêutico ocupacional. Barros (2004) ressalta que a noção de atividades terapêuticas no âmbito social deve ser redefinida para constituir-se em instrumento para a emancipação cultural e afetiva dessas pessoas, grupos e comunidades, portanto, o teatro torna-se um recurso significativo na terapia ocupacional social.

\section{CONSIDERAÇÕES FINAIS}

Os resultados da análise evidenciaram que o grupo constituiu-se em um espaço singular de encontro, experimentação e construção de si, que reverberou no adolescente a percepção dele mesmo como um ser engajado na sociedade, detentor de um papel, com potencial para criar e transformar.

Diante do que é preconizado por Moreno (1992), o teatro provocou no adolescente em risco social maior co-responsabilidade para viver em relações, sendo capaz de se colocar no lugar dos outros, e maior criatividade e espontaneidade para exercer papéis protagonizadores de mudanças.

De acordo com o que foi exposto por Boal (1990, 2009), afirma-se que o adolescente descobriu que pode ser não só espectador, mas autor e ator de sua própria vida, sendo capaz de se autodirigir em sua ação sobre o mundo, e descobrir o que sempre foi e teve, mas que estava adormecido pelo modo de vida da sociedade contemporânea: potência transformadora.

A atividade teatral, vivenciada no grupo terapêutico ocupacional, potencializou as capacidades de criatividade, espontaneidade e transformação social da clientela do estudo, modificando as atitudes que tinham frente a si mesmos e à sociedade em que viviam, para dar-lhes o sentido de um viver com auto-direcionamento, ancorado na percepção de uma coletividade pela qual são coresponsáveis. Desta forma, é possível notar a funcionalidade do teatro enquanto recurso terapêutico ocupacional com o adolescente em risco social, todavia são necessários maiores estudos sobre o tema.

Espera-se que esta pesquisa sirva de contribuição para as outras que se dedicam à relação entre terapia ocupacional e práticas artísticas como o teatro a fim de que as potencialidades destas linguagens sejam mais bem entendidas e, cada vez mais, aplicadas com propriedade no cotidiano terapêutico ocupacional. Segundo Barros et al. (2002), é preciso superar a concepção do terapeuta ocupacional como profissional exclusivamente da saúde, separando-se do paradigma de fundação, que vincula exclusivamente a Terapia Ocupacional à mediação saúdedoença.

E por fim, Almeida (2004) ressalta que o fazer e suas atividades, ao produzirem novas subjetividades, também podem construir novas sociedades. É dessa forma que a Terapia Ocupacional encontra seu papel político, negando as práticas serializadas e esterilizantes da vida, e construindo novas sociedades ao lado da diversidade e do sonho de um amanhã mais digno para o ser humano, em todas as suas raças, classes e trejeitos.

JUSTA, F. M. C.; HOLANDA, I. C. L. C. Theater with adolescents at social risk: Health promotion practices in an occupational therapy context. Rev. Ter. Ocup. Univ. São Paulo, v. 23, n. 1, p. 1623, jan./abr. 2012.

\begin{abstract}
The objective of this study was to analyze the usage of the artistic language of theater as a health promotion tool for adolescents at social risk, in an occupational therapy context. This process was carried out through the GESTTO group (Socio-theatrical expressions in Occupational Therapy), which was made up of teenaged residents from a community in the city of Fortaleza, Ceará. The investigation method used a qualitative and research-action approach based on the writings of Liberman, Barros, Boal and Moreno. The analysis results highlighted that the occupational therapy group allowed the adolescent to perceive himself/herself as a being in society, with a role to play, and with the potential to create and become an agent for transformation. Therefore, the functionality of theater as an occupational therapy resource is addressed.
\end{abstract}

KEYWORDS: Adolescents; Vulnerability; Culture; Art; Occupational therapy; Health promotion. 


\section{REFERÊNCIAS}

ABECHE, R.; INADA, J.; ARAÚJO, J. Os Percalços Enfrentados pelos Adolescentes na Construção da Subjetividade na Contemporaneidade. In: ENCONTRO LATINO AMERICANO DOS ESTADOS GERAIS, 4.; 2005.

ABERASTURY, A. O Adolescente e a liberdade. In: ABERASTURY, A.; KNOBEL, M. Adolescência normal: um enfoque psicanalítico. Porto Alegre: Artes Médicas, 1981. p. 13-21.

ALMEIDA, M.V.M. Corpo arte e movimento em terapia ocupacional. Rio de Janeiro: ENELIVROS, 2004.

ANTONI, C.; KOLLER, S. H. Vulnerabilidade e resiliência familiar: um estudo com adolescentes que sofreram maus tratos intrafamiliares. Psico, Porto Alegre, v. 31, n. 1, p. 39-66, 2000.

BARROS, D. D.; GHIRARD, M. I. G.; LOPES, R. E. Terapia ocupacional social. Rev. Ter. Ocup. Univ. São Paulo, v. 13, n. 3, p.95-103, 2002.

BARROS, D.; LOPES, R.; GALHEIGO, S. Terapia ocupacional social: concepções e perspectivas. In: CAVALCANTI, G. Terapia ocupacional fundamentação e prática. Rio de Janeiro: Guanabara Koogan; 2007. p.347-353.

BOAL, A. Estética do oprimido. Garamond, 2009.

BOAL, A. O arco-íris do desejo: método Boal de teatro e terapia. Rio de Janeiro: Civilização Brasileira, 1990.

BRASIL. Conselho Nacional de Secretários de Saúde. Atenção Primária e Promoção da Saúde. Conselho Nacional de Secretários de Saúde. Brasília: CONASS, 2007. v.8.

CASTRO, E. Arte, corpo e terapia ocupacional: aproximações, interseções e desdobramentos. Rev. Ter. Ocup. Univ. São Paulo, v. 15, n. 1, p. 7-12, 2000.

CHIZZOTTI, A. Pesquisa em ciências humanas e sociais. São Paulo: Cortez, 2006.

COVAS, C.; MEDONÇA, M. Teatro espontâneo: canal de expressão e instrumento terapêutico. O COFFITO, set., 2003.

DALL'ORTO, F. C. O teatro do oprimido na formação da cidadania. Fênix - Rev. História Est. Culturais, UFERJ UNIRIO, v. 5, n. 2, p. 1-16, 2008. Disponível em: www. revistafenix.pro.br. Acesso em: 27 out. 2008.

HOLANDA, I. C. L. Ações educativas na estimulação precoce: analise do desempenho das mães no cuidado diário. 2004. [dissertação]. Fortaleza (CE): Universidade de Fortaleza, 2004.

JUSTA, F. M. Instrumento de coleta de dados da pesquisa intitulada Teatro com adolescentes em risco social: práticas de promoção da saúde no contexto terapêutico ocupacional: diário de campo. Fortaleza, 2009.

LEOPARDI, T. M. Metodologia da pesquisa na saúde. Santa Maria: Pallotti, 2001.

LEVISKY, D. L. Aspectos do processo de identificação do adolescente na sociedade contemporânea e suas relações com a violência. In: LEVISKY, D. L. Adolescência e violência: conseqüências da realidade brasileira. São Paulo: Casa do Psicólogo, 2000.

LIBERMAN, F. Danças em terapia ocupacional. São Paulo: Summus, 1998.

LIBERMAN, F. Trabalho corporal, música, teatro e dança em Terapia Ocupacional: clínica e formação. Cadernos - Centro Universitário S. Camilo, São Paulo, v. 3, n. 3, p. 39-43, 2002.

MINAYO, M. C. S. Pesquisa social: teoria, método e criatividade. Petrópolis, RJ: Vozes, 1994.

MORENO, J. L. Psicodrama. São Paulo: Editora Cultrix, 1975.

OLIVEIRA, M. C. Identidade, narrativa e desenvolvimento na adolescência: uma revisão crítica. Psicol. Estud., v. 11, n. 2, p. 427-436, 2006.

PEDRAL, C.; BASTOS, P. Terapia ocupacional - metodologia e prática. Rio de Janeiro: Editora Rubio, 2008.

ROZENTHAL, E. Uma outra cena: aproximações entre a psicanálise e teatro para uma perspectiva dos novos sintomas. Tempo Psicanalítico,Rio de Janeiro, v. 38, p. 119-142, 2006.

SAITO, M. I. Adolescência, cultura, vulnerabilidade e risco. A prevenção em questão. Rev. Psicopedagogia, v. 19, n. 57, p.9-13, 2001.

SILVA, S. C.; AVELINO, R. R. As diferenças sócio-econômicas e culturais interferem na construção da identidade do adolescente. Intercursos: Rev. Univ. Acad. Fundação Educ. Ituiutaba, v. 3, n. 1, p.4-10, 2004.

THIOLLENT, M. Metodologia da pesquisa-ação ação. São Paulo: Cortez, 1994. 